\title{
Adherence to treatment in asthma and COPD patients in their doctors' assessment
}

The authors declare no financial disclosure

\begin{abstract}
Introduction: Adherence to therapy is one of the basic preconditions of successful treatment of asthma and COPD. Unfortunately, many patients take their medication incorrectly. The aim of this study was to assess doctors' knowledge of this phenomenon, including interventions able to improve patient adherence.

Materials and methods: It was a questionnaire-based survey conducted among convenience sample of Polish physicians treating asthma and COPD.

Results: One hundred and sixty one physicians, mainly specialists in allergology (44.1\%) and pulmonology (37.3\%) took part in the study. According to participants, asthma patients took on average $65.4 \pm 17.1 \%$ of doses of prescribed drugs, whereas COPD patients $-61.6 \pm 24.2 \%$. Over half of respondents claimed that during the first year of treatment, no more than $20 \%$ of asthma and COPD patients discontinue their therapy. Survey participants pointed at patients discourage $(41.6 \%)$ and lack of knowledge about disease $(19.3 \%)$ as the main reasons for discontinuation of therapy. Almost $2 / 3$ of participants $(65.8 \%)$ claimed that they could recognize non-adherence in their patients. Prescribing combination inhaled drugs $(72.7 \%)$, drugs with infrequent dosing $(63.4 \%)$, and affordable ones (53.4\%) were the most common interventions aimed at improving adherence provided by respondents. Conclusions: Survey participants were aware of the phenomenon of non-adherence in patients with asthma and COPD, but underestimated the real prevalence and seriousness of it. They also overestimated their ability to recognise non-adherence in their patients. Therefore, not necessarily they may obtain better adherence in their asthma and COPD patients. These results point at the issues which should be addressed in pre- and postgraduate education of physicians treating chronic airways conditions.
\end{abstract}

Key words: asthma, COPD, non-adherence, compliance

Pneumonol Alergol Pol 2015; 83: 436-444

\section{Introduction}

Non-adherence to medical recommendations consists in various deviations made by patients from treatment schedule that had been agreed with health professionals [1]. Due to high prevalence and serious consequences of the phenomenon, WHO has considered the problem "a global issue of crucial significance" [2]. As it has been repeatedly shown, at least $50 \%$ of patients with chronic illnesses do not adhere to prescribed therapy. According to the studies conducted in
Poland, the phenomenon is even more prevalent among Poles: in the group of 63,000 study subjects suffering from different chronic diseases, as many as $\mathbf{8 3 . 8 \%}$ admitted to non-adherence to prescribed regimen [3].

Non-adherence to recommended therapy reduces the effectiveness of treatment and increases the costs of medical care [2]. Therefore, of importance is the awareness of factors that promote non-adherence, and the delivery of interventions that increase patient adherence to therapy, particularly in the case of most frequent, so the most 
important from the public health view, chronic illnesses. Such diseases undoubtedly include asthma and chronic obstructive pulmonary disease (COPD), for they affect over 300 million people worldwide $[4,5]$.

Non-adherence to prescribed therapy in asthma results in worse disease control and more frequent exacerbations. In addition, it leads to poor patients' quality of life, a greater demand for medical services, including more frequent hospitalizations, and increased mortality. It also constitutes a vital source of costs incurred by health care systems. Non-adherence to therapy in case of COPD brings about similar effects, being one of the main reasons for ineffective treatment of the disease and related costs [6-10].

Doctors do have their role in ensuring that patients adhere to prescribed regimen. On the one hand, it is important to undertake routine actions aimed at preventing non-adherence to prescribed drugs. Such actions include among the others providing patients with information about objectives and methods of treatment in a manner that would create in them the motivation for starting and continuing the therapy. On the other hand, there is a need to actively search for the cases of non-adherence to medical regimen in order to promptly deliver appropriate interventions [6].

Although the problem in question is of higher importance, there are merely few studies concerning the awareness of doctors and their actions aimed at enhancing patients adherence during asthma and COPD therapy [8, 11]. The studies carried out in Poland have found that primary health providers are not fully aware of the spread of the problem, and do not know the interventions that could limit the range of the phenomenon [12]. The objective of the study was an attempt to assess the awareness of non-adherence to prescribed therapy of health professionals who treat patients with asthma and COPD in Poland, and to learn the interventions they deliver to improve the regularity of treatment in this group of patients.

\section{Material and methods}

The study was based on an anonymous and voluntary questionnaire survey conducted among doctors treating patients with asthma and COPD. The original questionnaire constructed for this study (see Annex 1) included 10 questions concerning the issues related to patients adherence to asthma and COPD therapy, and 3 questions about the subjects' characteristic (age, sex, and specialist medical training). The questionnaire was made available at a dedicated surveying website (SurveyMonkey). The information about the study along with the link to the questionnaire was made available to doctors who registered for the scientific conference on allergology and pulmonology $\left(18^{\text {th }}\right.$ Scientific and Training Conference "Advances in Allergology and Pulmonology", Cracow, 2012). The experimental part of the study was conducted between 1 June and 5 November 2012.

As many physicians who took the survey had more than one specialisation, they were assigned post factum to one of three groups:

- "lung disease specialists taking care of children" - the group included doctors who apart from specialisation in allergology or lung diseases, took paediatrics as one of their specialist trainings,

- "lung disease specialists not taking care of children" - the group included doctors who had at least one of the following specialisations: allergology, lung diseases (pulmonology), but not paediatrics,

— "others" - the group included all remaining doctors who answered to the question about specialisation.

Data collected in online survey were transferred to a special database, and then analysed using standard methods of descriptive analysis. The results were presented as percentage of all study subjects, unless otherwise specified. Differences between the answers to questions given by "lung disease specialists taking care of children" and "lung disease specialists not taking care of children" were assessed with the help of chi ${ }^{2}$ test (for qualitative variables) and Kruskal-Wallis test (for quantitative variables), assuming $\mathrm{p}<0.05$ as statistically significant.

\section{Results}

161 doctors, including 115 women (71.4\%) participated in the study. The mean age of the respondents was $51.2 \pm 8.6$ years. Doctors with specialisation in allergology $(44.1 \%)$ and lung diseases (37.3\%) predominated. 14 persons $(8.7 \%$ of the subjects) have not provided information on their specialisation, and this group has not been taken into account in statistical calculations concerning correlations between the chosen parameters concerning specialisation. Detailed characteristic of the subjects is presented in Table 1.

According to the respondents, the percentage of prescribed doses taken by their patients averaged $65.4 \pm 17.1 \%$ for patients with asthma, 
Table 1. Characteristics of the study subjects

\begin{tabular}{|c|c|c|c|}
\hline & & $\mathbf{n}$ & $\%$ \\
\hline Age (years) & Mean ( \pm standard deviation) & \multicolumn{2}{|c|}{$51.2( \pm 8.6)$} \\
\hline Sex & $\begin{array}{c}\text { Female } \\
\text { Male } \\
\text { No data available }\end{array}$ & $\begin{array}{l}115 \\
34 \\
12\end{array}$ & $\begin{array}{c}71.4 \\
21.1 \\
7.5\end{array}$ \\
\hline Specialisation $^{*}$ & $\begin{array}{c}\text { Allergology } \\
\text { Lung diseases } \\
\text { Paediatrics } \\
\text { General medicine } \\
\text { Internal diseases } \\
\text { Others } \\
\text { No data available }\end{array}$ & $\begin{array}{c}71 \\
60 \\
7 \\
5 \\
3 \\
1 \\
14\end{array}$ & $\begin{array}{c}44.1 \\
37.3 \\
4.3 \\
3.1 \\
1.9 \\
0.6 \\
8.7\end{array}$ \\
\hline The study group ${ }^{\#}$ & $\begin{array}{l}\text { Lung disease specialists taking care of children } \\
\text { Lung disease specialists not taking care of children } \\
\text { Others } \\
\text { No data available }\end{array}$ & $\begin{array}{c}54 \\
85 \\
8 \\
14\end{array}$ & \\
\hline Total & & 161 & 100.0 \\
\hline
\end{tabular}

"specialisation indicated by the respondent as main (first) specialisation; " the study group was classified ex post basing on information about specialisations, see "Material and methods"

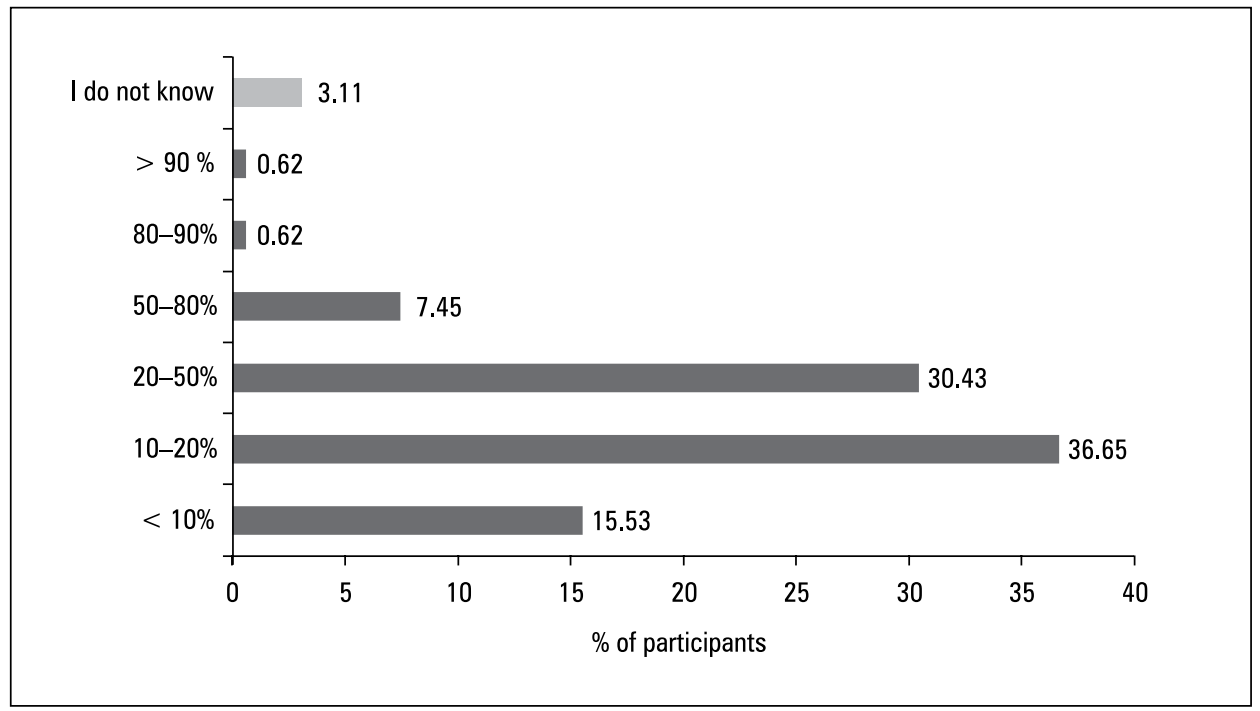

Figure 1. The proportion of patients who, according to the study subjects, stop their treatment for asthma within 12 months since diagnosis. The proportions were calculated for all study subjects $(n=161)$. The diagram does not include the group "no answer available" $(n=9)$

and $61.6 \pm 24.2 \%$ for COPD patients. Over half of the study subjects have claimed that therapy of asthma and COPD is stopped within the first 12 months of treatment by not more than $20 \%$ of patients (52.2\% and 50.9\%, respectively). The proportion of patients who stop therapy within the first 12 months the most often was assessed at $10-20 \%$ among asthmatic patients $336.6 \%$ of answers), and among COPD patients - most often at $10 \%$ (27.3\% of answers) (Fig. 1 and 2). More than $1 / 5$ of the doctors surveyed (21.7\%) were not able to give the proportion of patients who stopped treatment of COPD within the first year of therapy - which was probably related to the lack of personal experience with this group of patients (25 doctors out of 36 subjects who gave such an answer, belonged to the group of "lung disease specialists taking care of children”).

According to the respondents, the main causes of stopping the therapy by asthma and COPD patients were first of all discouragement of patients (41.6\%), insufficient knowledge about the disease (19.3\%), and less frequently - lack of noticeable for the patient effects of treatment, and the price of drugs $(6.2 \%$ and $5.6 \%$, respectively, Figure 3). Whereas the proportion of patients with 


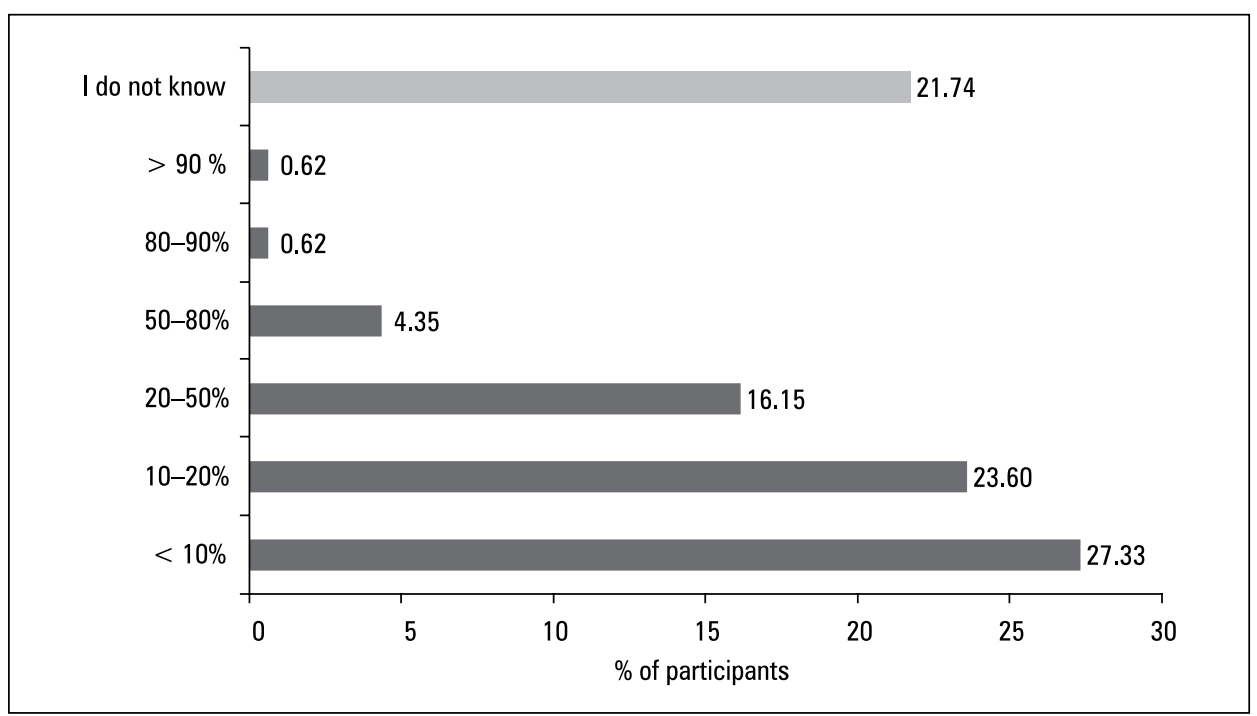

Figure 2. The proportion of patients who, according to the study subjects, stop their treatment for COPD within 12 months since diagnosis. The proportions were calculated for all study subjects $(n=161)$. The diagram does not include the group "no answer available" $(n=9)$

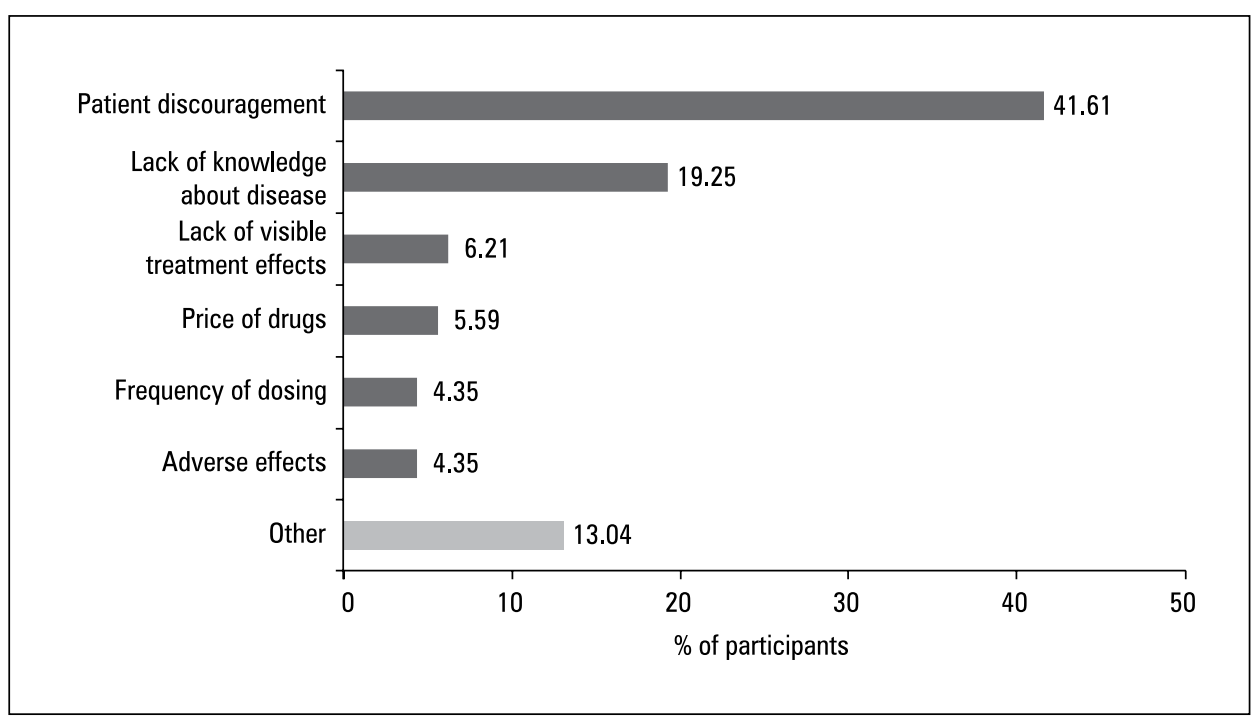

Figure 3. Main reasons for discontinuation of treatment for asthma and COPD according to the respondents. The proportions were calculated for all study subjects $(n=161)$. The diagram does not include the group "no answer available" $(n=9)$

asthma and COPD that at least once did not buy medication due to its price within the preceding 12 months was quite small: in opinion of $42.9 \%$ of the respondents such a situation occurred in less than $10 \%$ of patients, and according to $31.1 \%$ of the respondents - in $10-50 \%$ of patients. Barely $4.3 \%$ of the respondents answered that such case could have happened among $50 \%$ or greater percentage of patients.

The doctors surveyed were also asked, whether they were able to recognise non-adherence to treatment in their patients. Nearly $2 / 3$ of the respondents (65.8\%) claimed that they could do so "in most of cases", and 9.3\% — "practically in every case”. Every fifth doctor declared that he/ she had difficulties in recognising non-adherence to therapy among their patients $(18.6 \%$ were able to recognise non-adherence "in the minority of cases", and barely $3.7 \%$ of the respondents admitted that they were not able to do so). Similarly, the majority of respondents maintained that they asked their patients about adherence to treatment $-72.7 \%$ of respondents answered that they ask about it during each consultation, and merely $1.9 \%$ - that they seldom ask about it, and $1.2 \%$ - that they never ask about it. The respondents also declared that when they discovered that recently ordered therapy was ineffective, 




Figure 4. Interventions made by the doctors surveyed in case of ineffectiveness of the previously prescribed therapy (the respondents were to define the frequency of their interventions, from the most frequent to the least frequent)

at first they took actions in order to assess and exclude possible problems related to regularity of treatment $(61.5 \%$ of respondents listed it as the most frequently taken action), and the other most often taken interventions included: increasing dosage of medication, adding another drug to the therapy, and the exchange of the medication with another one from the same therapeutic group, in accordance with the guidelines (Figure 4).

Finally, the respondents were also asked to indicate interventions they made to improve their patients' adherence to therapy. The most frequent actions were as follows: prescribing combination drugs (72.7\% of respondents), choosing medication with infrequent administration (63.4\%) and prescribing inexpensive drugs (53.4\%).

The differences between the answers given by "lung disease specialists taking care of children" and "lung disease specialists not taking care of children" that would meet the criteria of statistical significance $(p<0.05)$ were not found. The exception was the assessment of the percentage of drugs taken by COPD patients: "lung disease specialists taking care of children" evaluated this percentage significantly lower than "lung disease specialists not taking care of children" (54.4 \pm $26.4 \%$ vs. $66.0 \pm 22.0 \%, p<0.01$, respectively).

\section{Discussion}

Adherence to therapy in asthma and COPD treatment is of crucial importance for both individuals and the whole population. Non-adherence in these conditions is connected with patients' poor quality of life, lower productivity, increased morbidity and mortality, and bigger demand for medical services and extra costs [13]. Therefore, it is important for doctors treating patients with chronic lungs diseases - pulmonologists, allergologists, and general practitioners - to be aware of the magnitude of the problem, and be able to react accordingly.

However, the present study has shown that physicians overestimate degree to which patients adhere to prescribed regimen. Both the estimate of average percentage of drug doses taken by patients and of the percentage of patients who stop their treatment (numerous doctors believed that barely $10-20 \%$ of patients stop therapy during the first 12 months of treatment) were considerably overstated. In many authors' opinion, the majority of patients with chronic airways conditions do not adhere to the treatment - as far as COPD is concerned, it applies to as many as $60-80 \%$ of patients $[14,15]$. Particularly serious consequences are related to complete discontinuation of therapy. According to the literature, $40 \%$ of COPD patients stop their treatment after 30 days, and $70 \%$ of them discontinue it within the first 90 days from initiation [16]. The analysis of the regularity of treatment with inhaled drugs in Poland confirms these tendencies: according to observations, at least $40 \%$ of Polish patients discontinue therapy after 3 months of treatment for COPD, and for asthma - even 70\% [17].

One of the possible explanations of this discrepancy is the fact that it may be difficult for doctors to accept that a considerable amount 
of their patients do not adhere to their instructions. It is contrary to what doctors can observe in everyday practice: the patients visit them and accept prescriptions. Therefore physicians tend to see the problem among other patients who are treated by the other healthcare professionals. This explains the fact that, as it has been found in the present study, "lung disease specialists taking care of children" - so having rare contact with COPD patients - expected that these patients stop therapy more often, compared to doctors who take care of these patients on a daily basis.

A systematic review carried out recently has shown numerous reasons for which patients do not adhere to prescribed regimens [18]. In the case of asthma and COPD, some patients do not treat their disease seriously [19], some patients stop their therapy when symptoms disappear [20] or because they think that the therapy is too complex [21], others are afraid of possible adverse drug reactions, and that the drug will not work during subsequent exacerbation [22]. The evaluation of reasons for which patients stop treatment for asthma and COPD made by doctors participating in the present study was realistic. The most vital causes of non-adherence are discouragement of patients, in particular in the case of lack of visible effects of treatment, and insufficient knowledge about the disease.

A significant role in non-adherence to medical recommendations in Poland, especially in case of expensive medication, may be played by financial factors. Although essential drugs used in asthma and COPD are relatively inexpensive for the insured patient, some medication may pose financial problems to many (e.g. monthly therapy with tiotropium will cost the majority of patients more than PLN 40.00). Thus it may be assumed that the opinions of the respondents did not correspond perfectly with the range of the phenomenon - a survey conducted in 2012 revealed that as many as $27 \%$ of Poles declared that they did not buy prescribed medication due to financial reasons [23].

More than 2/3 of the respondents believed that they were able to recognise non-adherence to treatment in the majority of their patients. Unfortunately, as it has been proved on many occasions, doctors are not able to assess the degree of their patients' adherence to therapy, even though they know and treat them for many years [24].

A definite majority of respondents declared that they ask their patients about the regularity of treatment at every visit. Although such method is easy and readily available, it is not a precise tool to assess adherence to treatment. Numerous studies have proved that information obtained from patients is biased due to their subjectivity. It happens frequently that patients, in order to satisfy their doctors, overestimate adherence to their therapy $[25,26]$. To verify whether the patient adheres to treatment, it is possible to count taken doses, or check if he or she systematically buys prescribed medication. Another approach may be based on controlling the patient's biological markers or using electronic drug monitoring [27].

Despite all these limitations, the fact that doctors often ask their patients about their adherence to therapy is encouraging, as effective communication between the doctor and patient is crucial for proper adherence to medical recommendations $[11,26]$. The fact of asking about adherence puts an emphasis on the role of treatment regularity in successful therapy, also it additionally motivates patients to adhere to prescribed regimen. Furthermore, it is a good starting point for the identification of barriers to adherence and elimination thereof [28]. The whole process may make use of typology drawn up by Rand [29], who described three types of non-adherence to prescribed regimen and proposed specific solutions to them. According to this typology, an "irregular patient" understands the therapy, accepts it but does not adhere to it due to too tight day schedule, forgetfulness, lack of attention for small matters. In such a case, simplifying the drug regimen and monitoring medication adherence by third parties may be helpful. An "unaware patient" unintentionally misinterprets treatment instructions, e.g. because of language barriers, cultural differences or other ailments (dementia, depression, worries). Education and written instructions regarding the drug regimen may be the most helpful for such patients. The third type of patient is called "intelligent" - it characterises persons who intentionally do not take drugs due to their negative beliefs regarding their efficacy, adverse effects and toxicity. In such a case, good doctor-patient communication presenting benefits related to the therapy may positively influence adherence.

What is important, in case of non-adherence, the respondents declared that they were focusing on the improvement of its regularity, and not the modification of the therapy. It is vital because the choice of effective medication in the therapy of asthma and COPD is not particularly wide, and together with the recommendations of the clinical practice guidelines, it does not allow to radically change the therapy. Unfortunately, the compari- 
son of these declarations with the results of the analysis of nationwide database of pharmacy claims leaves no doubts as to the fact that such interventions are ineffective, taking into account that not more than $13 \%$ of asthmatic patients and $21 \%$ of COPD patients take inhaled drugs systematically over the period of 12 months, on average [17].

Improved regularity of treatment is vital, taking into consideration that adherence to therapy in asthma and COPD is poorer than in other chronic conditions [30]. The most popular intervention to enhance adherence declared by the doctors interviewed was prescribing combination inhaled drugs. Their decision based on rational assumptions, for there are studies confirming the effectiveness of improved adherence to medical recommendations with combination inhalers, compared to the same drugs taken separately, both in asthma [31] and COPD [32]. However, such a correlation has not been found in the Polish setting: the already mentioned analysis of national database of pharmacy claims has not shown more regular or persistent treatment of asthma or COPD by patients taking combination drugs, compared to those using inhaled betamimetics and corticosteroids in two separate inhalers [17].

In order to improve adherence to therapy, the respondents were also choosing other interventions of proven effectiveness such as prescribing medication of infrequent dosing. Less frequent dosing does improve adherence to treatment, both in asthma and COPD [33, 34]. In general, it has been observed that the less frequent administration of drugs, the better adherence to prescribed regimen, and this rule applies also to drugs administered once and twice a day [35].

The present study has its obvious limitations. The way in which the study group has been chosen does not guarantee that it is representative. According to the Central Statistical Office of Poland [Główny Urzqd Statystyczny], 1,384 doctors with specialisation in lung diseases worked in 2012 in Poland [36]. Approximately 9\% of them participated in the present study, which may be satisfying taking into account survey-based form of the study. In addition, the fact that the study included doctors participating in the scientific and training conference, could impact on deeper, than in most of doctors, awareness of the study subject.

\section{Conclusions}

The doctors interviewed were aware of non-adherence to medical recommendations of patients with asthma and COPD, but they underestimated its real prevalence. They also undervalued the financial side of the problem. On the other hand, they overestimated their ability to recognise non-adherence to treatment in their patients and they took remedial actions that do not guarantee a real improvement in adherence. These results indicate the issues that should be approached in pre- and postgraduate education of health professionals dealing with therapy of asthma and COPD.

\section{Conflict of interest}

The authors declare no conflict of interest.

\section{References:}

1. Vrijens B, De Geest S, Hughes DA et al. ABC Project Team. A new taxonomy for describing and defining adherence to medications. Br J Clin Pharmacol 2012; 73: 691-705. doi: 10.1111/j. 1365-2125.2012.04167.x.

2. Adherence to long-term therapies. Evidence for action. World Health Organisation 2003.

3. Kardas P. Rozpowszechnienie nieprzestrzegania zaleceń terapeutycznych wśród pacjentów leczonych z powodu wybranych schorzeń przewlekłych. Pol Merk Lek 2011; 184: 215-220.

4. To T, Stanojevic S, Moores G. Global asthma prevalence in adults: findings from the cross-sectional world health survey. BMC Public Health 2012; 12: 204. doi: 10.1186/1471-2458-12-204.

5. Vos T, Flaxman AD, Naghavi $M$ et al. Years lived with disability (YLDs) for 1160 sequelae of 289 diseases and injuries 1990-2010: a systematic analysis for the Global Burden of Disease Study 2010. Lancet 2012; 380: 2163-2196. doi: 10.1016/ S0140-6736(12)61729-2.

6. Bourdin A, Halimi L, Vachier I et al. Adherence in severe asthma. Clin Exp Allergy 2012; 42: 1566-1574. doi: 10.1111/j.13652222.2012.04018.x.

7. Bender BG, Rand C. Medication non-adherence and asthma treatment cost. Curr Opin Allergy Clin Immunol 2004; 4: 191-195.

8. Robinson DS, Campbell DA, Durham SR, Pfeffer J, Barnes PJ, Chung KF. Systematic assessment of difficult-to-treat asthma Eur Respir J 2003; 22: 478-483.

9. Williams LK, Pladevall M, Xi $\mathrm{H}$ et al. Relationship between adherence to inhaled corticosteroids and poor outcomes among adults with asthma. J Allergy Clin Immunol 2004; 114: 1288-1293

10. Cooke CE, Sidel M, Belletti DA, Fuhlbrigge AL. Review: clinical inertia in the management of chronic obstructive pulmonary disease. COPD 2012; 9: 73-80. doi: 10.3109/15412555.2011.631957.

11. Restrepo RD, Alvarez MT, Wittnebel LD et al. Medication adherence issues in patients treated for COPD. Int J Chron Obstruct Pulmon Dis 2008; 3: 371-384

12. Kardas P, Ratajczyk-Pakalska E. Świadomość problemu niestosowania się pacjentów do zaleconej terapii wśród lekarzy podstawowej opieki zdrowotnej regionu łódzkiego. Polska Med Rodz 2000; 2: 151-157.

13. Mäkelä MJ, Backer V, Hedegaard M, Larsson K. Adherence to inhaled therapies, health outcomes and costs in patients with asthma and COPD. Respir Med 2013; 107: 1481-1490. doi: 10.1016/j.rmed.2013.04.005.

14. Haupt D, Krigsman K, Nilsson JL. Medication persistence among patients with asthma/COPD drugs. Pharm World Sci 2008; 30: 509-514. doi: 10.1007/s11096-008-9197-4.

15. Huetsch JC, Uman JE, Udris EM, Au DH. Predictors of adherence to inhaled medications among Veterans with COPD. J 
Gen Intern Med 2012; 27: 1506-1512. doi: 10.1007/s11606012-2130-5.

16. Jung E, Pickard AS, Salmon JW, Bartle B, Lee TA. Medication adherence and persistence in the last year of life in COPD patients. Respir Med 2009; 103: 525-534. doi: 10.1016/j. rmed.2008.11.004.

17. Kardas P, Czeleko T, Śliwczyński A. Ciągłość i systematyczność leczenia astmy i POChP w Polsce - ocena przestrzegania zaleceń terapeutycznych na podstawie analizy krajowej bazy danych realizacji recept. Proceedings of The $10^{\text {th }}$ International Conference of the Polish Pharmacoeconomics Society - ISPOR Poland Chapter, Warsaw, 2012.

18. Kardas P, Lewek P, Matyjaszczyk M. Determinants of patient adherence: a review of systematic reviews. Front Pharmacol 2013; 4: 91. doi: 10.3389/fphar.2013.00091.

19. DiMatteo MR, Haskard KB, Williams SL. Health beliefs, disease severity, and patient adherence: A meta-analysis. Med Care 2007; 45: 521-528.

20. Menckeberg TT, Bouvy ML, Bracke M, Hugtenburg JG, Lammers JW, Raaijmakers JA. Patients' understanding of the reasons for starting and discontinuing inhaled corticosteroids. Br J Clin Pharmacol 2008; 66: 255-260. doi: 10.1111/j.13652125.2008.03168.x.

21. Krigsman K, Moen J, Nilsson JL, Ring L. Refill adherence by the elderly for asthma/chronic obstructive pulmonary disease drugs dispensed over a 10-year period. J Clin Pharm Ther 2007; 32: 603-611.

22. Le TT, Bilderback A, Bender B et al. Do asthma medication beliefs mediate the relationship between minority status and adherence to therapy? J Asthma 2008; 45: 33-37. doi: 10.1080/02770900701815552.

23. Sondaż TNS OBOP dla Wiadomości 09.10.2012, http://tvp. info/informacje/polska/co-czwartego-pacjenta-nie-stac-na-le$\mathrm{ki} / 8759289$.

24. Zeller A, Taegtmeyer A, Martina B, Battegay E, Tschudi P. Physicians' ability to predict patients' adherence to antihypertensive medication in primary care. Hypertens Res 2008; 31 : 1765-1771. doi: 10.1291/hypres.31.1765.

25. Lareau SC, Yawn BP. Improving adherence with inhaler therapy in COPD. Int J Chron Obstruct Pulmon Dis 2010; 24: 401-406. doi: 10.2147/COPD.S14715.
26. George J, Kong DC, Thoman R, Stewart K. Factors associated with medication nonadherence in patients with COPD. Chest 2005; 128: 3198-3204.

27. Bender B, Wamboldt FS, O'Connor SL et al. Measurement of children's asthma medication adherence by self report, mother report, canister weight, and Doser CT. Ann Allergy Asthma Immunol 2000; 85: 416-421.

28. Barnestein-Fonseca P, Leiva-Fernández J, Vidal-España F, García-Ruiz A, Prados-Torres D, Leiva-Fernández F. Is it possible to diagnose the therapeutic adherence of patients with COPD in clinical practice? A cohort study. BMC Pulm Med 2011; 11: 6. doi: 10.1186/1471-2466-11-6.

29. Rand C. "I took the medicine like you told me, doctor": Self-report of adherence with medical regimens. In: Stone AA, Turkkan JS, Bachrach CA et al. (eds.) The science of self-report: Implications for research and practice. Mahwah, NJ: Lawrence Erlbaum 1999; 257-276.

30. Krigsman K, Nilsson JL, Ring L. Adherence to multiple drug therapies: refill adherence to concomitant use of diabetes and asthma/COPD medication. Pharmacoepidemiol Drug Saf 2007; 16: $1120-1128$.

31. Stoloff SW, Stempel DA, Meyer J, Stanford RH, Carranza Rosenzweig JR. Improved refill persistence with fluticasone propionate and salmeterol in a single inhaler compared with other controller therapies. J Allergy Clin Immunol 2004; 113: 245-251.

32. Fenton C, Keating GM. Inhaled salmeterol/fluticasone propionate: a review of its use in chronic obstructive pulmonary disease. Drugs 2004; 64: 1975-1996.

33. Price D, Robertson A, Bullen K, Rand C, Horne R, Staudinger H. Improved adherence with once-daily versus twice-daily dosing of mometasone furoate administered via a dry powder inhaler: a randomized open-label study. BMC Pulm Med 2010; 10: 1. doi: 10.1186/1471-2466-10-1.

34. Toy EL, Beaulieu NU, McHale JM et al. Treatment of COPD: relationships between daily dosing frequency, adherence, resource use, and costs. Respir Med 2011; 105: 435-441. doi: 10.1016/j.rmed.2010.09.006.

35. Claxton AJ, Cramer J, Pierce C. A systematic review of the association between dose regimens and medication compliance. Clin Ther 2001; 23: 1296-1310.

36. Główny Urząd Statystyczny. Rocznik statystyczny Rzeczypospolitej Polskiej 2013. Warszawa 2013.

\section{Annex 1. The questionnaire used in the study}

\section{We kindly ask you to complete a short, anonymous questionnaire that will allow to know the problems You encounter during Your everyday practice with patients with ASTHMA and COPD.}

- What do You usually do in the case of ineffectiveness of recent, relatively newly prescribed therapy? Please arrange the answers from the most frequent to the least frequent interventions, assigning to them the numbers from 1 to 4 ( 1 - the most frequent interventions, $4-$ the least frequent interventions).

- I increase the dose of the administered drug/drugs (if possible)

- I change the drug to another one from the same or another therapeutic group, according to the guidelines

- I add a subsequent drug that is indicated as complementary/additional treatment for the disease

- I make interventions that allow to assess and eliminate possible problems of the patient's adherence to treatment

- Are you able to recognise the patient's non-adherence to the therapy?

- Non, I am not

- I am able to recognise it in the minority of cases

- I am able to recognise it in the majority of cases

- I am able to recognise it almost in all cases 
— Do You ask Your patients about adherence to their treatment?

- Non, never

- Rarely

- Often

- I do, almost at every visit

- What percentage of drug doses do Your patients with asthma take?

- What percentage of drug doses do Your patients with COPD take?

- What percentage of Your patients stop treatment of ASTHMA within 12 months since diagnosis?

- Less than $10 \%$

- $10-20 \%$

- $20-50 \%$

- $50-80 \%$

- $80-90 \%$

- More than 90\%

- I don't know

- What percentage of Your patients stop treatment of COPD within 12 months since diagnosis?

- Less than $10 \%$

- $10-20 \%$

- $20-50 \%$

- $50-80 \%$

- $80-90 \%$

- More than 90\%

- I don't know

- What is in your opinion the main reason for stopping treatment by patients with asthma and COPD?

- Adverse effects of drugs

- Price of drugs

- The frequency of drugs' administration

- Lack of noticeable to the patient effects of treatment

- Reluctance of patients to treat systematically

- Inadequate patients' awareness of the disease and the treatment conducted

- Others

- What percentage of Your patients with ASTHMA and COPD did not buy drugs within the previous 12 months at least once due to the price of the drugs?

- Less than $10 \%$

- $10-50 \%$

- $50-90 \%$

- More than 90\%

- I don't know

- Do You use any methods to enhance Your asthmatic and COPD patients' adherence to the therapy? (many options are possible)

- I try to prescribe drugs with short names

- I try to prescribe inexpensive drugs

- I try to prescribe combination inhaled drugs including more than one active substance in one dose

- I try to prescribe inhaled drugs not including glucose

- I try to prescribe drugs with infrequent dosing

Please, complete with Your personal data

- Age

- Sex

- Woman

- Man

- Specialisation

- Thank You for completing the questionnaire 